\title{
PENERAPAN METODE DIRECT SEARCH PADA SISTEM INFORMASI SEJARAH PAHLAWAN SULAWESI SELATAN BERBASIS ANDROID
}

\section{UTILIZATION OF DIRECT SEARCH METHOD ON INFORMATION SYSTEM OF SOUTH SULAWESI HERO HISTORY BASED ON ANDROID}

\author{
Nur Mustika ${ }^{1}$, Pujianti Wahyuningsih ${ }^{2}$ \\ ${ }^{1}$ STMIK Handayani Makassar \\ ${ }^{2}$ STMIK Handayani Makassar \\ 1'mustika@handayani.ac.id, ${ }^{2}$ ujiwahyuningsih@handayani.ac.id
}

\begin{abstract}
Abstrak
Perlunya pemahaman generasi muda tentang sejarah pahlawan nasional Indonesia menjadi faktor penting untuk menumbuhkan rasa nasionalisme generasi muda bangsa Indonesia khususnya daerah Sulawesi Selatan. Salah satu cara yang dapat dilakukan untuk dapat menumbuhkan rasa nasionalisme generasi muda adalah dengan memanfaatkan teknologi Android untuk memberikan informasi sejarah pahlawan Bangsa Indonesia. Tujuan Penelitian ini adalah membangun sistem informasi sejarah pahlawan daerah Sulawesi Selatan berbasis Android dengan menggunakan metode direct Search. Metode direct search adalah metode pencarian langsung untuk menyelesaikan suatu permasalahan tanpa membutuhkan informasi tambahan. Hasil dari penelitian ini adalah sistem informasi yang dibangun dapat digunakan oleh masyarakat untuk memberikan informasi mengenai sejarah pahlawan nasional khususnya daerah Sulawesi Selatan, Indonesia.
\end{abstract}

Kata kunci : Pahlawan, Direct Search, Android

\begin{abstract}
The necessary of young generation knowledge about the Indonesian hero's history is very important to grow their nationalism, especially the young generation in the South Sulawesi of Indonesia. One of the ways can be used to grow the nationalism of the young generation are by utilization of Android technology to give information about the history of Indonesian heroes. The purpose of this study is to build the information system of Indonesian heroes based on Android using direct search method. The direct search method is the method is able to use to search the information by directly to solve the problem without need additional information. The result of this study is the information system was developed is able to use to the society to give the information about the national hero history especially in the South Sulawesi of Indonesia.
\end{abstract}

Keywords: Heroes, Direct search, Android.

\section{PENDAHULUAN}

Negara Indonesia adalah negara yang mempunyai keragaman budaya, adat istiadat, bahasa dan sejarah kepahlawanan. Salah satu provinsi yang mempunyai keanekaragaman adat-istiadat, budaya dan sejarah kepahlawanannya adalah daerah provinsi Sulawesi Selatan. Adapun suku budaya pada provinsi Sulawesi Selatan adalah Suku Mandar, Bugis, Toraja, Makassar, Maiwa, Endekan, Pattinjo, Duri, Endekan, Kajang dan Pattae. Suku tersebut tersebar di beberapa kota dan kabupaten yang memiliki sejarah kepahlawanannya masing-masing. Seiring perkembangan zaman, generasi 
Jurnal Elektro Luceat [July] [2020]

muda banyak yang kurang mengetahui sejarah pahlawan terkhsusnya provinsi Sulawesi Selatan. Generasi muda memilki peran penting dalam memperkenalkan sejarah kepahlawanan sejak dini, dimana pengenalan tersebut untuk menumbukan dan menanamkan rasa nasionalisme dan cinta kepada tanah air bangsa Indonesia.

Negara Indonesia memiliki banyak pahlawan yang telah berjasa mengusir penjajah demi kemerdekaan bangsa Indonesia, terdapat banyak pahlawan nasional yang ada di Indonesia khususnya daerah Sulawesi Selatan. Adapun beberapa pahlawan yang terdapat di Sulawesi Selatan antara lain Arung Palakka, Sawerigading, Sultan Hasanuddin, La Galigo, Andi Djemma, Emmy Saelan, Opu Daeng Risadju, La madukelleng, Pong Tiku, Ranggong daeng room, Andi Pangeran Pettarani, Andi Abdullah Bau Massepe, Andi Sultan Daeng Radja, dan sebagainya. Setiap pahlawan ini memiliki kisah yang tersebar disetiap daerah. Beberapa peneliti telah melakukan penelitian tentang sejarah pahlawan nasional Indonesia. Pada penilitian [1], peneliti telah membuat aplikasi pengenalan pahlawan berbasis multimedia dengan menggunakan metode pembelajaran konvensional yang diaplikasikan kepada siswa MI AL-GINA. Pada penelitian [2], peneliti meracang permainan kartu eduktif untuk mengetahui sejarah pahlawan Indonesia dengan memberikan informasi berupa gambargambar menarik untuk anak usia 7-9 tahun. Pada penelitian [3], peneliti membuat aplikasi pengenalan pahlawan melalui mata uang Indonesia berbasis AR dengan menampilkan 3D. Pada penelitian [4], peneliti membuat game untuk mengetahu sejarah kapitan pattimura berbasis android. Pada penelitian [5], peneliti merancang Aplikasi untuk mengenal pahlawan untuk menumbuhkan rasa nasionalis berbasis android pada siswa SDN 104238 dengan tujuan sebagai media pembelajaran.

Pada penelitian ini peneliti akan membangun sistem informasi sejarah pahlawan daerah Sulawesi selatan berbasis android dengan menggunakan metode direct search. Penelitian ini bertujuan untuk memberikan pemahaman kepada masyarakat terutama generasi muda tentang sejarah pahlawan provinsi Sulawesi Selatan berbasis mobile android. Pemanfaatan mobile android memberikan manfaat bagi generasi muda dan masyarakat karena sangat mempermudah dalam memperoleh informasi yang dapat diakses kapanpun dan dimanapun dengan mobile phone. Metode pada penelitian ini mempermudah peneliti dalam memecahkan masalah tanpa memerlukan informasi dan tentang gradient fungsi tujuan.

\section{MATERIAL DAN METODOLOGI}

\subsection{Metode direct search}

Direct Search merupakan metode yang digunakan untuk menyelesaikan sebuah masalah dan tidak membutuhkan informasi apapun[6]. Metode ini digunakan untuk meminimalkan fungsi yang mempunyai nilai nyata dengan transformasi nilai baru dan tiga operasi berbasis simpleks[7] dengan menggunakan filter dan frame [8]. Dalam menyelesaikan masalah, metode ini dapat dianalasis dengan mudah menggunakan derivative[9].

Cara kerja metode direct search pada penelitian ini adalah pada saat user atau pengguna ingin mencari data informasi tentang pahlawan, maka sistem akan langsung mengarahkannya ke tampilan informasi tanpa harus mencarinya menggunakan database. Sistem akan sangat mudah dan cepat digunakan karena tidak memerlukan pencarian yang lama pada saat user atau pengguna ingin melihat data tersebut. Pada sistem informasi yang telah dibangun, terdapat langkah-langkah yang diterapkan sehingga metode direct search dapat diaplikasikan pada penelitian ini. Berikut ini adalah flowcart sistem yang diusulkan untuk memberi informasi sejarah pahlawan nasional Sulawesi selatan menggunakan metode direct search. 
JEC Vol. 6 No. 1

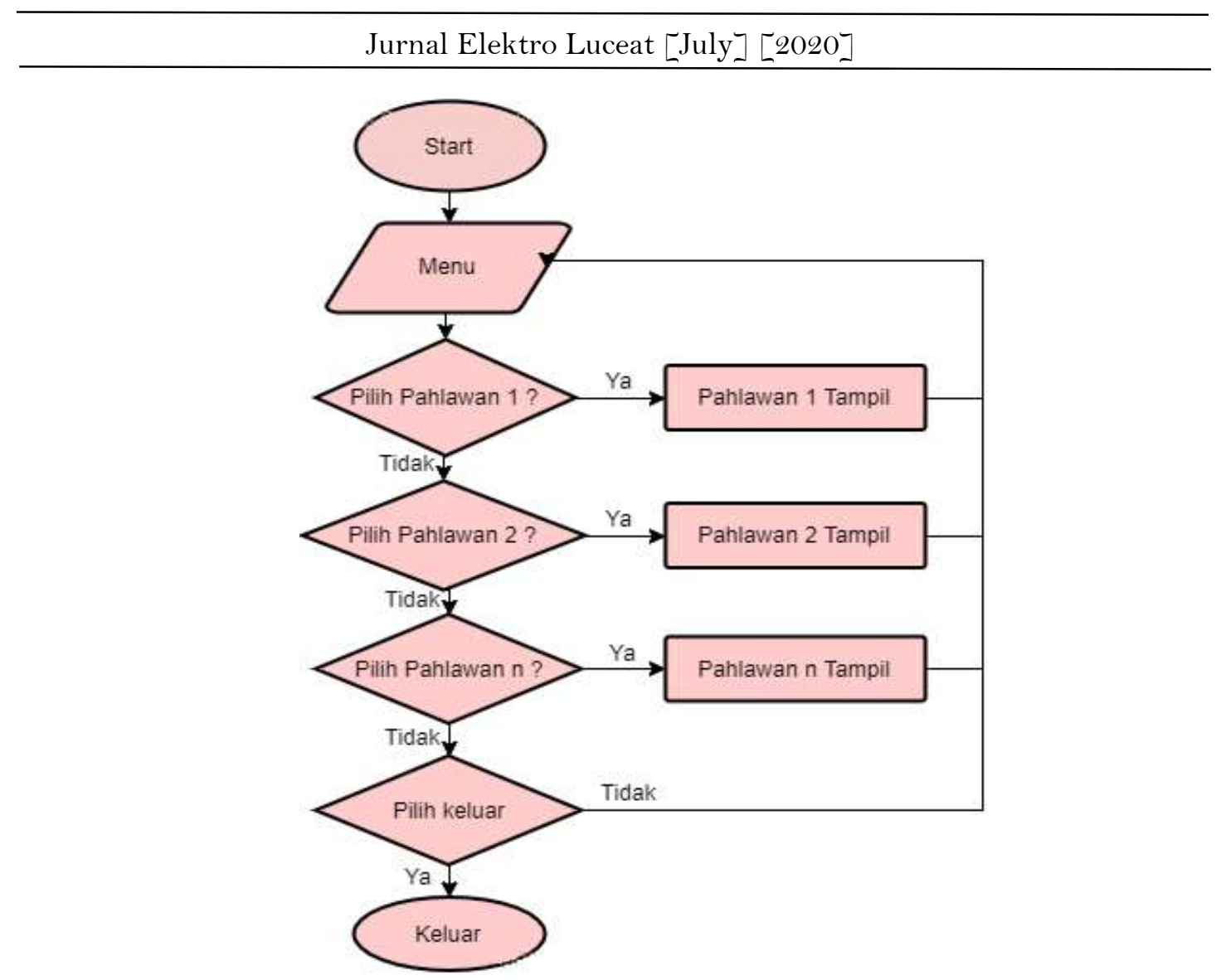

Gambar 1. Flowcart metode direct search

Berdasarkan informasi metode direct search yang ditampilkan pada algoritma yang dipaparkan di gambar 1, langkah awal yang dilakukan oleh user adalah membuka aplikasi sejarah pahlawan, kemudian muncul tombol menu dan nama-nama pahlawan Nasional Sulawesi Selatan. Pada saat pengguna memilih pahlawan 1 untuk dibaca sejarahnya, maka sistem yang telah dibangun akan langsung mengarahkan user agar dapat membaca sejarah pahlawan nasional sesuai dengan nama pahlawan masing-masing. Sistem ini akan terus berjalan hingga sistem informasi dihentikan atau dikeluarkan oleh penggguna.

\subsection{Android}

Android merupakan sistem operasi berbasis linux yang menyediakan platform terbuka yang digunakan pada smartphone dan tablet[10]. Android telah digunakan pada penelitian sebelumnya seperti aplikasi untuk mengenalkan alat music tradisonal yang terdapat didaerah-daerah seluruh Indonesia[11]. Pada penelitian[12], peneliti menjelaskan aplikasi berbasis android digunakan untuk mengidentifikasi terumbu karang dengan animasi 3D. Pada penelitian[13], peneliti memesan tiket bus sehingga pembeli tidak perlu mengunjungi loket pemesanan tiket dengan menggunakan platform android. Pada penenlitian ini, peneliti akan membuat aplikasi untuk mengetahui sejarah pahlawan daerah Sulawesi Selatan berbasis android.

\subsection{Pahlawan Nasional}

Pahlawan nasional merupakan gelar yang di berikan kepada seseorang karena telah berjuang melawan penjajah dimana mereka menghasilkan sebuah prestasi dari membela bangsa dan 
negaranya[3]. Salah satu pahlawan nasional Indonesia terdapat pada targedi pengkhianatan Partai Komunis Indonesia (PKI) G30S/PKI yang merupakan pahlawan revolusi[14]. Pada penelitian ini, peneliti akan membuat sistem informasi sejarah pahlawan daerah Sulawesi Selatan berbasis android dengan menggunakan metode direct search. Beberapa pahlawan nasional yng berasal dari Sulawesi Selatan diantaranya adalah Arung Palakka, Sawerigading, Sultan Hasanuddin, La Galigo, Andi Djemma, Emmy Saelan, Opu Daeng Risadju, La madukelleng, Pong Tiku, Ranggong daeng room, Andi Pangeran Pettarani, Andi Abdullah Bau Massepe, Andi Sultan Daeng Radja,

\section{PEMBAHASAN}

Sistem informasi pahlawan daerah Sulawesi selatan yang dibangun dalam peneltian ini dapat dinstall dan diakses oleh masyarakat secara offline. Masyarakat dapat langsung menginstall sistem informasi yang telah dibangun ke perangkan smartphode Android. Langkah awal yang dilakukan dalam sistem ini adalah memasukkan semua informasi data pahlawan nasional Sulawesi selatan secara langsung ke aplikasi tanpa menggunakan database. Setelah admin memasukkan seluruh informasi data, langkah selanjutnya adalah pengguna menginstalnya ke smartphone android kemudian membuka aplikasi tersebut. Berikut adalah tampilan awal saat sistem informasi sejarah pahlawan nasional daerah Sulawesi Selatan pada saat pertama dibuka oleh pengguna atau user.

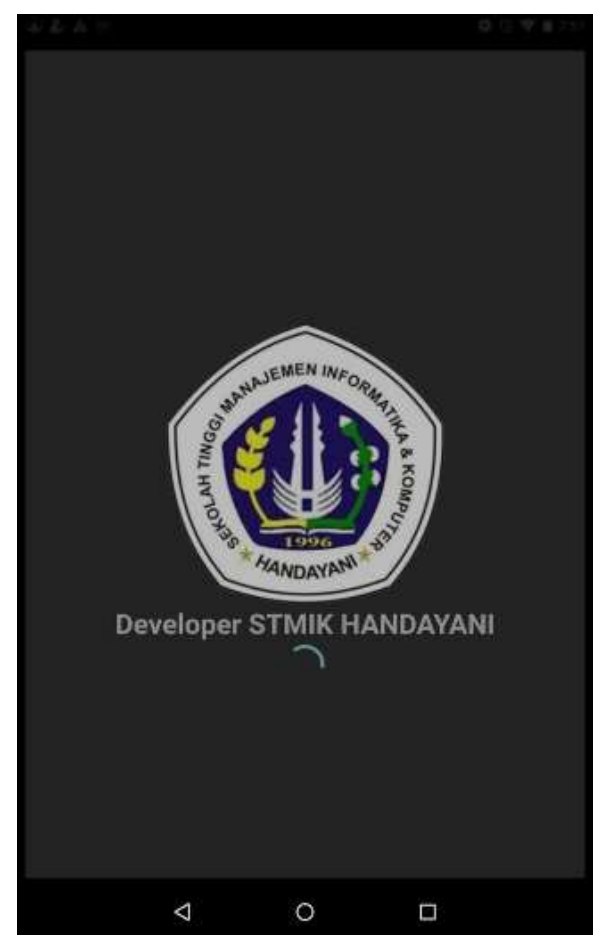

Gambar 2. Tampilan login sistem

Berdasarkan gambar 2 dapat dilihat bahwa tampilan awal dari sistem informasi pada saat pengguna atau user pertama kali membuka aplikasi sistem informasi pahlawan nasional daerah Sulawesi Selatan. Sistem akan loading sampai aplikasi yag di bangun benar-benar dapat terbuka oleh sistem. Hal ini dilakukan agar pengguna atau user diberi kesempatan untuk melihat informasi dari perangkat lunak yang dibangun. Berdasarkan informasi tersebut dapat dilihat bahwa sistem informasi sejarah pahlawan nasional Indonesia telah berhasil dibangun oleh developer dengan nama STMIK Handayani. 
Setelah pengguna membuka apliaksi, maka akan muncul halaman menu yang merupakan nama-nama pahlawan negara Indonesia khususnya daerah Sulawesi selatan. Berikut adalah gambar tampilan menu dari sistem informasi yang dibangun.

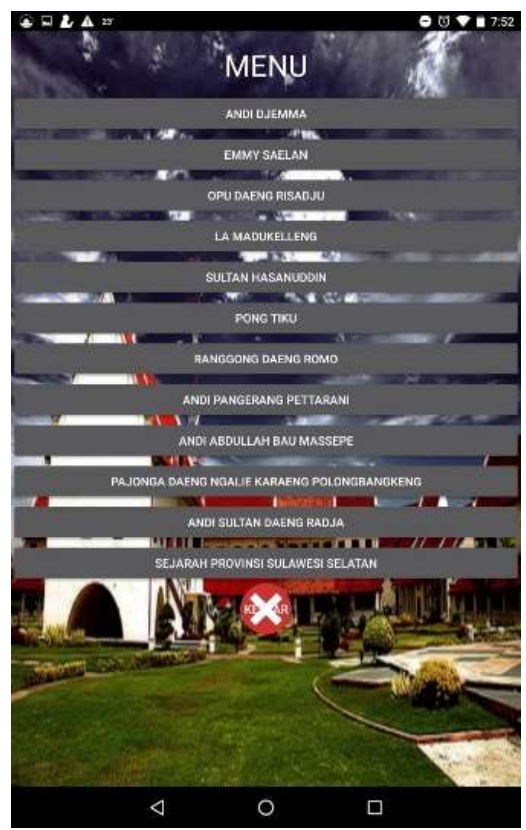

Gambar 3. Tampilan halaman utama sistem

Langkah selanjutnya setelah menampilkan tampilan menu adalah pengguna dapat memilih salah satu nama dari pahlawan tersebut. Setelah pengguna memilih salah satu nama dari sistem informasi tersebut, langkah selanjutnya pengguna dapat membaca dan melihat informasi sejarah dari pahlawan nasinal Indonesia. Berikut adalah salah satu tampilan form yang digunakan untuk menampilkan cerita sejarah pahlawan indonesia khususnya daerah Sulawesi Selatan.

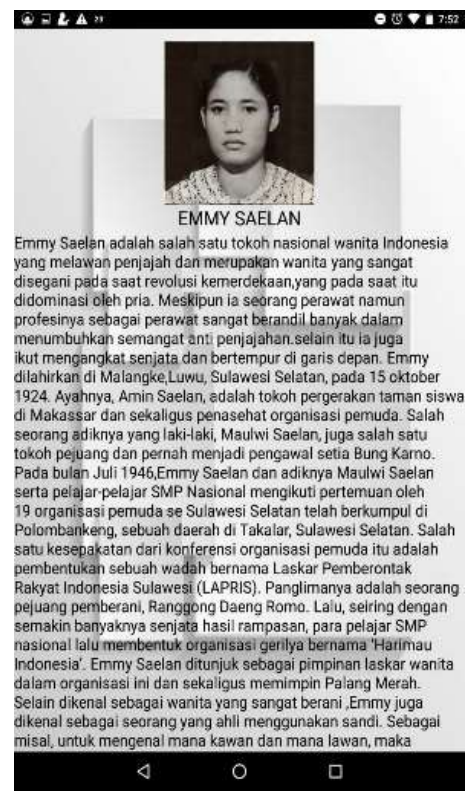

Gambar 4. Tampilan nama pahlwan beserta sejarahnya 
Selain menampilkan sejarah pahlawan daerah Sulawesi Selatan, aplikasi ini juga dapat memberikan informasi tetang daerah provinsi Sulawesi selatan. Berikut adalah tampilan informasi daerah provinsi Sulawesi Selatan

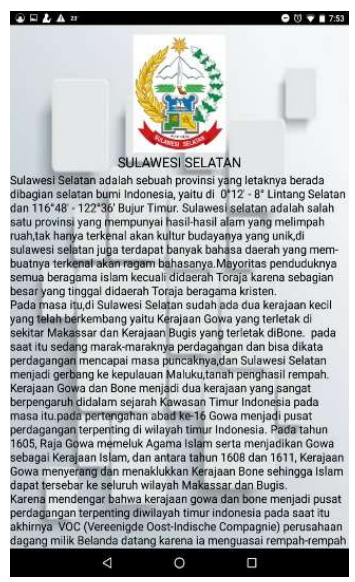

Gambar 5. Tampilan informasi Sulawesi Selatan

\section{KESIMPULAN}

Penggunaan sistem informasi sejarah pahlawan nasional berbasis Android mengunakan metode direct searh telah diaplikasikan pada penelitian ini. User atau pengguna dapat dengan mudah menggunakan aplikasi ini untuk membaca dan melihat informasi sejarah pahlawan nasional khususnya daerah Sulswesi Aselatan. Saran untuk pengembangan sistem selanjutnya adalah sistem informasi sejarah pahlawan nasional yang dibangun dapat diakses secara online

\section{TERIMA KASIH}

Terima Kasih kami ucapkan kepada KEMENRISTEK DIKTI dan STMIK Handayani Makassar yang telah memberikan bantuan dan supportnya sehingga Penelitian Dosen Pemula (PDP) dapat kami selesaikan dengan baik.

\section{DAFTAR PUSTAKA}

[1] Budiman, A., Triono dan Ariani, D. 2014. Aplikasi Interaktif Pengenalan Pahlawan Revolusi Indonesia Berbasis Multimedia (Studi Kasus di MI AL-GINA). JURNAL SISFOTEK GLOBAL, Vol. 4, No. 2.

[2] Wibowo, TP. 2014. Perancangan Permainan Kartu Edukatif Untuk Memperkenalkan Sejarah Dan Pahlawan Kemerdekaan Indonesia PAda Anak Usia 7-9 Tahun. Jurnal Desain Komunikasi Visual Adiwarna.

[3] Seto, MHN., Listyorini, T dan Susanto, A. 2015. Pengenalan Pahlawan Indonesia Berbasis Augmented Reality Dengan Marker Uang Indonesia. Prosiding SNATIF ke-2, ISBN: 978602-1180-21-1.

[4] Fidiyanto, D., Listyorini, T dan Nurkamid, M. 2015. Game Sejarah Perjuangan Kapitan Pattimura Berbasis Android. Prosiding SNATIF ke-2, ISBN: 978-602-1180-21-1. 
JEC Vol. 6 No. 1

Jurnal Elektro Luceat [July] [2020]

[5] Tahel. F dan Ginting, E. 2019. Perancangan Aplikasi Media Pembelajaran Pengenalan Pahlawan Nasional Untuk Meningkatkan Rasa Nasionalis Berbasis Android. TEKNOMATIKA, Vol. 09, No. 02

[6] https://www.mathworks.com/help/gads/what-is-direct-search.html, [Online], diakses pukul 10.00, tanggal 9 Juni 2020.

[7] Baeyens, E., Herreros, A dan Peran, JR. 2016. A Direct Search Algorithm For Global Optimization. Algorithms 2016, 9,40; doi:10.3390/a9020040

[8] Dennis, JE., Price, CJ dan Coope, ID. 2004. Direct Search Methods for Nonlinearly Constrained Optimization Using Filters and Frames. Optimization and Engineering 5, 123 144.

[9] Kolda, TG., Lewis, RM. Dan Torczon, V. 2003. Optimization By Direct Search: New Perspectives on Some Classical and Modern Methods. SIAM REVIEW, Vol. 45, No.3, PP. 385-482.

[10] Murtiwiyati dan Lauren, G. 2013. Rancang Bangun Aplikasi Pembeljaran Budaya Indonesia Untuk Anak Sekolah Dasar Berbasis Android. Jurnal Ilmiah Komputasi, Vol. 12, No. 2, hal. $1-10$.

[11] Widianti, S., Setiadi, I dan Hermawan, HF. 2013. Aplikasi Pengenalan Alat Musik Tradisonal Berbasis Android. Jurnal Ilmiah Komputasi, Vol. 12, No. 2, hal. 11-18.

[12] Alifuddin, M., Zuhriyah. S., Wahyuningsih. P dan Asrul BEW. 2019. Implementation of $3 D$ Animation for Identification of Coral Reefs Based on Android Mobile Application. Semanticscholar.org

[13] Wahyuningsih, P dan Guntur. 2018. The Information System of Bus Ticket Reservation Based on Android Application To Manage The Company Business Management. International Conference and Call For Paper.

[14] Hendrawan, J dan Perwitasari, ID. 2019. Aplikasi Pengenalan Pahlawan Nasional dan Pahlawan Revolusi Berbasis Android. Jurnal Teknologi Informasi, Vol. 3, No. 1. 